\title{
GAY, Ruth, Geschichte der Juden in Deutschland. Von der Römerzeit bis zum Zweiten Weltkrieg
}

\section{Catherine Maurer}

\section{OpenEdition}

\section{Journals}

Édition électronique

URL : http://journals.openedition.org/ifha/1975

DOI : 10.4000/ifha.1975

ISSN : 2198-8943

\section{Éditeur}

IFRA - Institut franco-allemand (sciences historiques et sociales)

\section{Référence électronique}

Catherine Maurer, «GAY, Ruth, Geschichte der Juden in Deutschland. Von der Römerzeit bis zum Zweiten Weltkrieg », Revue de l'IFHA [En ligne], Date de recension, mis en ligne le 01 janvier 1994, consulté le 22 septembre 2020. URL : http://journals.openedition.org/ifha/1975; DOI : https://doi.org/10.4000/ifha. 1975

Ce document a été généré automatiquement le 22 septembre 2020.

(C)IFHA 


\title{
GAY, Ruth, Geschichte der Juden in Deutschland. Von der Römerzeit bis zum Zweiten Weltkrieg
}

\author{
Catherine Maurer
}

1 Voici un livre qui réussit à concilier les exigences des historiens avec les attentes d'un plus vaste public. L'auteur, qui n'est pas une universitaire à proprement parler, est l'épouse de Peter Gay, célèbre historien de la culture sous Weimar et, comme il est souligné dans l'ouvrage, survivant de la communauté à laquelle est consacré ce "monument «, au sens premier du terme. Monument mais pas mausolée: en moins de 300 pages, R.G. propose en effet une synthèse qui se refuse à faire de l'histoire des Juifs d'Allemagne une suite continue de persécutions, dont la fin »logique« aurait été l'Holocauste. Sans passer sous silence les expressions de l'antisémitisme, elle s'efforce donc de restituer, en ne négligeant pas les portraits d'individus, toute l'épaisseur de la vie sociale, politique, religieuse et culturelle de la communauté juive dans l'espace germanique, en consacrant une part importante à cette période qui, suivant le »retour à l'histoire« du XVIIIe s., a vu l'intégration grandissante des Juifs à la société allemande. Pour R.G. et son époux (qui a rédigé l'introduction), ce n'est pas parce que cet effort d'intégration a échoué tragiquement qu'il doit être vu par les Juifs eux-mêmes sous l'angle de la condamnation (à cause de la "trahison« qu'il représenterait vis-à-vis de la culture juive) ou sous l'angle du pathétique téléologique (les Allemands, au fond, n'auraient jamais voulu de cette intégration et l'auraient fait "payer" par l'extermination). En bref, l'auteur replace donc le devenir des Juifs allemands dans une véritable perspective historique, en le débarrassant des interprétations à portée théologique ou politique.

2 Ce qui redouble cependant l'intérêt du livre et lui permettra sans doute de s'évader du cercle fermé des bibliothèques, c'est la richesse de son iconographie. Le livre rassemble en effet 274 illustrations, dont 20 en couleur. Celles-ci nous mènent du premier document écrit dans lequel apparaissent les Juifs de l'espace germanique (un décret de l'empereur Constantin au IVe s.) jusqu'à l'»adieu«, symbolisé par la dernière mention 
figurant dans la chronique d'une paroisse juive de Prusse orientale, datant du 24 avril 1941 (»Zum Abschied«). Trois images sont cependant particulièrement frappantes. Deux d'entre elles sont l'expression de l'intégration: le tableau très "winterhaltérien« de la famille Strousberg (1870), qui figure une famille de la grande bourgeoisie que rien ne distingue $\mathrm{du}$ reste de sa classe sociale, et la photographie d'une Studentenverbindung juive (1907), dont les membres, bottés et armés, se présentent de la même façon que ceux d'autres Burschenschaften. La troisième au contraire montre de façon poignante l'exclusion en marche: il s'agit d'une photographie d'émigrants quittant le port de Bremerhaven en 1938. Les visages sont graves et, comme le souligne la légende, "personne ne leur dit au revoir«. L'auteur a cependant renoncé à toute représentation iconographique de la "solution finale«, préférant mettre l'accent sur la vie des nouveaux émigrants en Palestine: ainsi donne-t-elle à voir que l'histoire des Juifs ne s'est pas arrêtée avec l'Holocauste. Dans le même temps, elle souligne néanmoins que celle des "Juifs allemands « et qui se considéraient comme tels est bel et bien terminée: sans idéalisation, ni nostalgie, il appartient à l'historien de faire l'inventaire de ce "monde disparu«. Il nous semble que l'ouvrage de R.G. constitue un bon exemple de cette démarche lucide. 